\title{
Massive pericardial effusion and short stature caused by autoimmune hypothyroidism in a 9-year-old girl
}

\author{
Yun Hee Gyon, MD, \\ Heon-Seok Han, MD, PhD
}

Department of Pediatrics, Chungbuk National University College of Medicine, Cheongju, Korea
Received: 5 April, 2015

Revised: 11 May, 2015

Accepted: 1 June, 2015

\author{
Address for correspondence: \\ Heon-Seok Han, MD, PhD \\ Department of Pediatrics, Chungbuk \\ National University College \\ of Medicine, 410 Sunbong-ro, \\ Heungdeok-gu, Cheongju 361-763, \\ Korea \\ Tel: +82-43-269-6370 \\ Fax: +82-43-264-6620 \\ E-mail:hshan@chungbuk.ac.kr
}

\begin{abstract}
A 9-year-, 11-month-old girl was brought to the Emergency Department for sudden dyspnea caused by massive pericardial effusion. In addition to relative bradycardia despite impending cardiac tamponade, short stature, overweight, and hypercholesterolemia were clues for suspected hypothyroidism. During thyroxine supplementation, catch-up growth was incomplete by rapid skeletal maturation. The use of short-term growth hormone showed increased growth velocity. In conclusion, primary hypothyroidism should be included in the etiologic evaluation of pericardial effusion, especially when it is associated with relative bradycardia. Additional growth promoting therapy should be considered for incomplete catchup growth in prolonged hypothyroidism during thyroxine supplementation.
\end{abstract}

Keywords: Hypothyroidism, Cardiac tamponade, Bradycardia, Growth, Hypercholesterolemia

\section{Introduction}

The clinical findings of acquired hypothyroidism present insidiously with fatigue, constipation, decreased growth velocity, delayed bone age, compromised intellectual performance, obesity, myxedema, hyperlipidemia, peripheral neuropathy, and delayed or precocious puberty ${ }^{1,2}$. Small pericardial effusion is not an infrequent manifestation in primary hypothyroidism, but massive pericardial effusion is the uncommon complication of acquired hypothyroidism in children ${ }^{3}$. As cardiac tamponade is life-threatening hemodynamically, the prompt diagnosis and drainage of pericardial effusion should be performed. The most common and prominent manifestation of chronic acquired hypothyroidism in children is profound growth failure, which is severe and progressive ${ }^{4)}$. Thyroxine supplementation improves all the clinical signs and symptoms except for growth failure ${ }^{5,6}$. Accelerated growth often does not result in restoration of full growth potential, due to the rapid increase in skeletal age during the first 18 months of treatment ${ }^{4)}$.

This case report shows that autoimmune hypothyroidism in a prepubertal girl manifested as massive pericardial effusion, short stature, and hyperlipidemia. Even with thyroxine therapy, catch-up growth was incomplete by rapid increase in bone age. Growth hormone supplementation would improve restoration of the height deficit obtained during the hypothyroid state.

\section{Case report}

A 9-year-, 11-month-old girl with a history of sudden worsening dyspnea for one day was brought to the Emergency Department for one day. The previously healthy girl showed a weight increase of about $10 \mathrm{~kg}$ over the course of one year. However, there was no fatigue, 
constipation, or dry skin. Hypercholesterolemia was recently found in the school health examination, but no further workup was performed. On examination, she was dyspneic but not cyanotic. Her vital signs were as follows; respiratory rate, 22 breaths/min; pulse rate, 65 beats/min; and blood pressure, $105 / 57 \mathrm{mmHg}$. Oxygen saturation $\left(\mathrm{SaO}_{2}\right)$ was $100 \%$ in room air. She looked short but chubby, with a height of $120 \mathrm{~cm}(<3 \mathrm{rd}$ percentile, -2.61 height standard deviation score [HSDS]), weight $30 \mathrm{~kg}$ (25th percentile), and body mass index (BMI) 20.8 $\mathrm{kg} / \mathrm{m}^{2}$ (90th-95th percentile). Her midparental height was 161 $\mathrm{cm}(0.05$ HSDS). She had no goiter and was in the prepubertal state. On auscultation, heart sounds were soft and, distant, but there was no murmur.

The chest radiograph showed cardiomegaly with a waterbottle appearance. Sinus bradycardia with low voltages of the QRS complexes was noted in overall leads. On echocardiography, massive pericardial effusion around the heart was found, and fluctuating mitral inflow was recorded according to respiration (Fig. 1A). Complete blood count, electrolytes, renal function test, and urinalysis were normal. Serum total cholesterol was elevated at $526 \mathrm{mg} / \mathrm{dL}$, low-density lipoprotein was $476 \mathrm{mg} / \mathrm{dL}$, aspartate aminotransferase was $117 \mathrm{IU} / \mathrm{L}$, alanine aminotransferase was $126 \mathrm{IU} / \mathrm{L}$, and CPK (creatine phosphokinase) was $851 \mathrm{IU} / \mathrm{L}$ (normal, <167 IU/L). However, creatine kinase-myoglobin and troponin $\mathrm{T}$ were normal.

She was taken urgent pericardiocentesis, removing $110 \mathrm{~mL}$ of straw-colored fluid. Closed pericardiostomy was performed with a pericardial catheter (Fig. 1B), further draining $155 \mathrm{~mL}$, and the catheter was removed two days later. The pericardial fluid showed that lactate dehydrogenase was $416 \mathrm{IU} / \mathrm{L}$, glucose was $79 \mathrm{mg} / \mathrm{dL}$, protein was $5.6 \mathrm{~g} / \mathrm{dL}$, and white blood cell count was $80 / \mu \mathrm{L}$ (mononuclear cell $90 \%$, polymorphonuclear cell $10 \%$ ), indicating exudate. The gram staining and culture for bacteria including acid-fast bacilli with the fluid were all negative. The polymerase chain reaction test was also negative for cytomegalic virus, Herpes simplex virus, and Epstein-Barr virus. An antibody test for Coxachie $B$ virus was also negative.

Endocrine tests were performed for short stature, high BMI, high cholesterol, relative bradycardia, and unknown etiology of pericardial effusion. Thyroid function analysis showed raised thyroid-stimulating hormone $(\mathrm{TSH}>50 \mu \mathrm{U} / \mathrm{mL}$; normal range, $0.35-4.94 \mu \mathrm{U} / \mathrm{mL}$ ) associated with a decrease

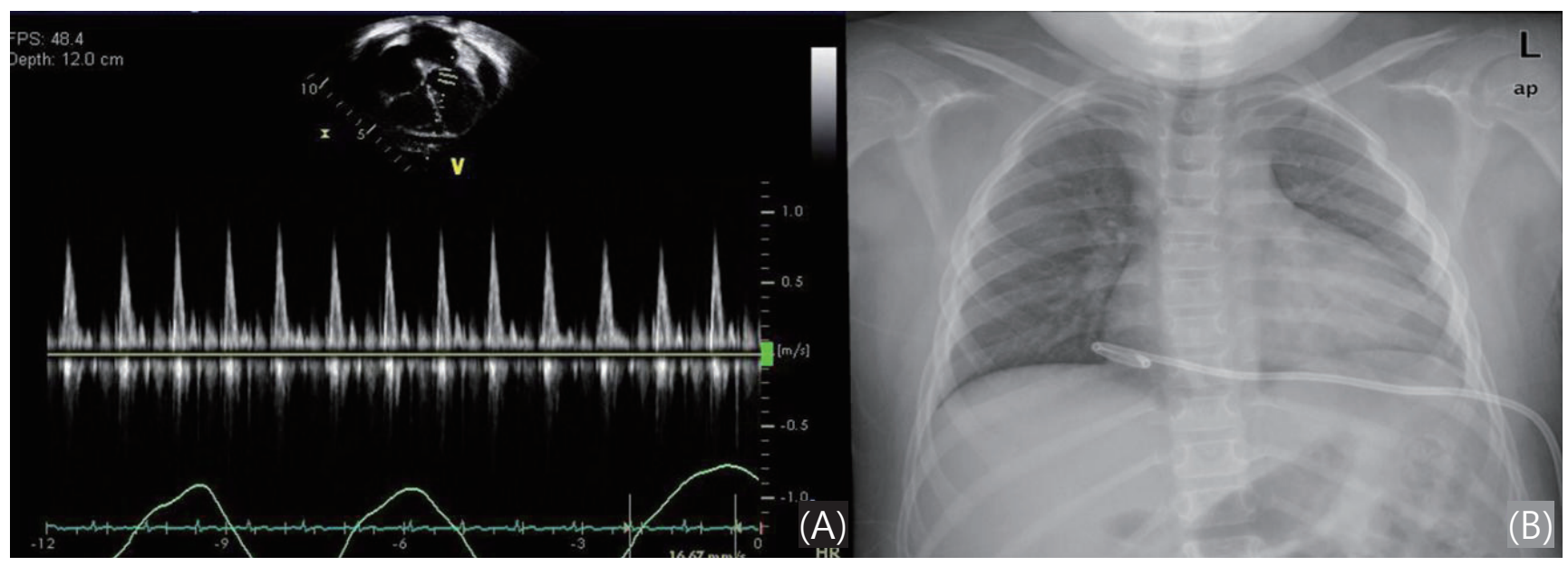

Fig. 1. Echocardiography revealed massive pericardial effusion around the heart and fluctuating mitral inflow pattern recorded according to respiration (A), and closed pericardiostomy was performed with pericardial catheter (B).
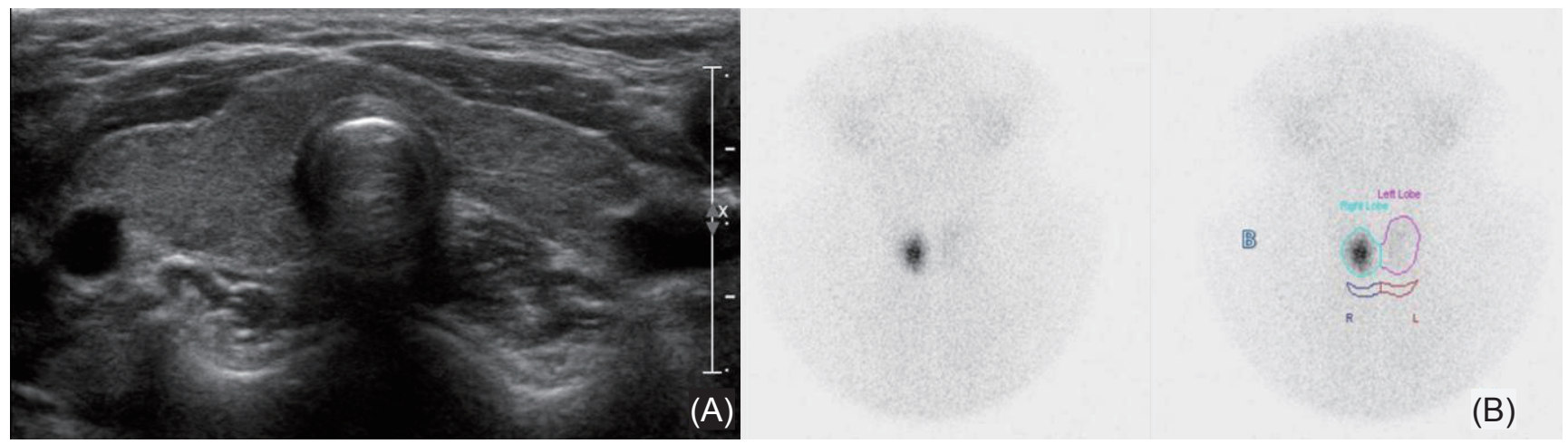

Fig. 2. Thyroid ultrasonography showed mild heterogeneous echogenicity without intrathyroid nodule and lymph node enlargement (A), and thyroid ${ }^{99 m}$ Tc scintigram showed focal increase of radio-uptake in right lobe and nearly non-visualization of left lobe (B). 
of free T4 (0.27 ng/dL; normal range, $0.7-1.48 \mathrm{ng} / \mathrm{dL})$ and T3 (56.9 $\mathrm{ng} / \mathrm{dL}$; normal range, $58.0-159 \mathrm{ng} / \mathrm{dL}$ ). Thyroid autoantibodies, including antithyroglobulin antibody $(154 \mathrm{IU} / \mathrm{mL})$, thyroid peroxidase antibody $(282 \mathrm{IU} / \mathrm{mL})$, and TSH-receptor antibody $(>40 \mathrm{U} / \mathrm{L})$ were all positive, indicating autoimmune hypothyroidism. Bone age was 9.0 years, which showed a one year delay for chronologic age. Insulin-like growth factor (IGF)-1 and insulin-like growth factor binding protein (IGFBP)-3 levels were low, at $63.6 \mathrm{ng} / \mathrm{mL}$ (normal range at 9-10 years; $64-345$ $\mathrm{ng} / \mathrm{mL}$ ) and $1,545 \mathrm{ng} / \mathrm{mL}$ (normal range at $9-10$ years; 1,800 $7,100 \mathrm{ng} / \mathrm{mL}$ ), respectively. Thyroid ultrasound showed mild heterogeneous echogenicity without intrathyroid nodule and lymph node enlargement (Fig. 2A). Thyroid ${ }^{99 \mathrm{~m}}$ Tc scintigram showed a focal increase of the radio-uptake in the right lobe and nearly nonvisualization of the left lobe (Fig. 2B).

Thyroid hormone was replaced with $0.1 \mathrm{mg}$ daily, and there was no recurrence of pericardial effusion since then. During the first year of thyroxine therapy, height velocity was $11.1 \mathrm{~cm} /$ $\mathrm{yr}$, the HSDS improved from -2.61 to -1.65 , and serum IGF1 and IGFBP-3 levels were increased to $579 \mathrm{ng} / \mathrm{mL}$ and 2,687 $\mathrm{ng} / \mathrm{mL}$ respectively. However bone age progressed rapidly from 9.0 years to 10.5 years. At 11 years of age, she developed breast budding with a bone age of 10.5 years. During the next 6 months, height velocity was $7.86 \mathrm{~cm} / \mathrm{yr}$ and HSDS increased only to -1.62 , but bone age progressed rapidly to 11.5 years. Growth hormone was given at $0.7 \mathrm{IU} / \mathrm{kg} / \mathrm{wk}$ for 6 months, resulting in increased HSDS up to -1.10 at the end of the second year of treatment with a height velocity of $12.63 \mathrm{~cm} / \mathrm{yr}$ (Fig. 3).

\section{Discussion}

This case is autoimmune hypothyroidism presenting as massive pericardial effusion with impending cardiac tamponade, which was demonstrated by the fluctuating mitral

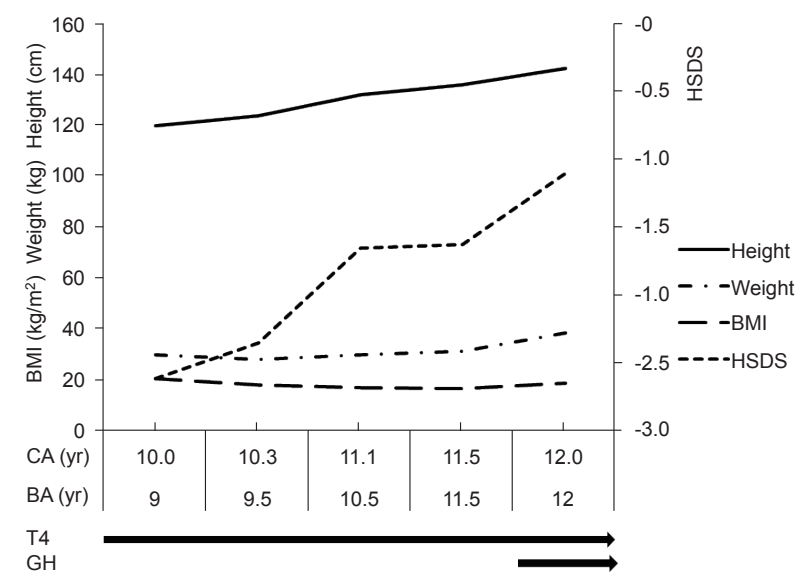

Fig. 3. Height standard deviation score (HSDS) improved during 1st year of thyroxine (T4) replacement with appropriate bone age (BA) progression. But during next 6 months, BA progressed rapidly without improvement of HSDS. Growth hormone was tried for the next 6 months with remarkable increase of HSDS. BMI, body mass index; CA, chronologic age. inflow of the Doppler pattern according to respiration. The relative bradycardia despite impending cardiac tamponade raised suspicion of a hypothyroid state. An endocrine test was performed to find the etiology of short stature, high BMI, and hypercholesterolemia. Clinical findings improved with thyroxine replacement, but catch-up growth was incomplete due to rapid skeletal maturation.

The incidence of newly diagnosed primary overt hypothyroidism among adults admitted through the Emergency Department is $0.1 \%$ in Taiwan. Most of the patients presented with nongoitrous autoimmune thyroiditis ( $21 \%$ of patients) and pericardial effusion (32\% of patients) in the winter time ${ }^{7}$. Previously undiagnosed hypothyroidism can manifest as a myxedema coma with shock due to tamponade, particularly in the winter, because cold environments can precipitate myxedema ${ }^{8)}$. Untreated long-standing hypothyroidism may evolve massive pericardial effusion in the case of child ${ }^{3)}$. Our case also manifested massive effusion in December with nongoitrous autoimmune thyroiditis. The serous pericardial fluid may have cholesterol crystals with mononuclear cell infiltrates ${ }^{9)}$. The mechanism of exudative pericardial effusion was thought to be a combination of the extravasation of albumin and inadequate lymphatic drainage ${ }^{10)}$.

A thyroid function test should be performed in the presence of bradycardia with cardiac tamponade, and the absence of tachycardia in the presence of persistent hypotension ${ }^{11,12)}$. In one report of the third recurrence of pericardial effusion, unexplained bradycardia, puffy face, and nonpitting pedal edema were clues for the diagnosis of hypothyroidism ${ }^{13}$. In our case, the clinical clues to suspect endocrine problems were short stature with high BMI, incidentally found hypercholesterolemia, and relative bradycardia in the presence of impending tamponade.

The low IGF-1 level in our case was a well-established phenomenon of decreased growth hormone secretion in severe hypothyroidism ${ }^{14)}$, which increased with thyroxine therapy. The HSDS increased rapidly during the first year, but then HSDS slowly progressed during the next half year with rapid bone age progression. Case reports of prolonged primary hypothyroid girl with growth failure and delayed puberty showed incomplete recovery of growth potential with only thyroxine therapy ${ }^{5,6)}$. The deficit in adult stature correlated with the duration of the hypothyroid state before treatment, so it is recommended to use a lower than usual replacement dosage of levothyroxine and/or to consider delaying puberty and epiphyseal fusion pharmacologically ${ }^{1)}$. In other reports of the combined use of growth hormone and gonadotropin-releasing hormone agonist, the final height of two patients with Hashimotos thyroiditis was improved ${ }^{15}$. However, a recent retrospective review suggested that neither time to euthyroidism nor the use of either gonadotropin-releasing hormone agonist or growth hormone significantly affected height potential ${ }^{16)}$. We used short-term growth hormone with some success.

Our case had no goiter despite autoimmune hypothyroidism, which might be explained by thyroid parenchymal fibrosis with 
prolonged lymphocytic infiltration ${ }^{6}$, which was inferred from the nonvisualization of the left lobe in a ${ }^{99 m} \mathrm{Tc}$ thyroid scintigram from our case.

In conclusion, primary hypothyroidism should be included in the etiologic evaluation of pericardial effusion, especially associated with relative bradycardia. Additional growth promoting therapy should be considered for incomplete catchup growth in prolonged hypothyroidism during thyroxine supplementation.

\section{Conflict of interest}

No potential conflict of interest relevant to this article was reported.

\section{References}

1. Rosenfeld RG, Cohen P. Disorders of growth hormone/ insulin-like growth factor secretion and action. In: Sperling MA, editor, Pediatric endocrinology. 3rd ed. Philadelphia: Saunders Elsevier, 2008:287-8.

2. Korean society of pediatric endocrinology. Pediatric endocrinology 3rd ed. Seoul: Koonja, 2014:205-9.

3. Williams LH, Jayatunga R, Scott O. Massive pericardial effusion in a hypothyroid child. Br Heart J 1984;51:231-2.

4. Rivkees SA, Bode HH, Crawford JD. Long-term growth in juvenile acquired hypothyroidism: the failure to achieve normal adult stature. N Engl J Med 1988;318:599-602.

5. Larson NS, Pinsker JE. Primary hypothyroidism with growth failure and pituitary pseudotumor in a 13-year-old female: a case report. J Med Case Rep 2013;7:149.

6. Kang SY, Park WS, Jung MJ, Lee YS, Park SG, Yu J. Two cases of acquired hypothyroidism with severe obesity, short stature and cardiomegaly. J Korean Soc Pediatr Endocrinol 2003;8:189-95.
7. Chen YJ, Hou SK, How CK, Chern CH, Lo HC, Yen $\mathrm{DH}$, et al. Diagnosis of unrecognized primary overt hypothyroidism in the ED. Am J Emerg Med 2010;28:86670 .

8. Ekka M, Ali I, Aggarwal P, Jamshed N. Cardiac tamponade as initial presenting feature of primary hypothyroidism in the ED. Am J Emerg Med 2014;32:683.e1-3.

9. Setty NS, Sadananda KS, Nanjappa MC, Patra S, Basappa $\mathrm{H}$, Krishnappa S. Massive pericardial effusion and cardiac tamponade due to cholesterol pericarditis in a case of subclinical hypothyroidism: a rare event. J Am Coll Cardiol 2014;63:1451.

10. Shastry RM, Shastry CC. Primary hypothyroidism with pericardial tamponade. Indian J Pediatr 2007;74:580-1.

11. Sanda S, Newfield RS. A child with pericardial effusion and cardiac tamponade due to previously unrecognized hypothyroidism. J Natl Med Assoc 2007;99:1411-3.

12. Mokta J, Mokta K, Panda P, Sharma M, Bhatia V. A swinging heart. Indian J Endocrinol Metab 2013;17(Suppl 3):S660-1.

13. Purkait R, Prasad A, Bhadra R, Basu A. Massive pericardial effusion as the only manifestation of primary hypothyroidism. J Cardiovasc Dis Res 2013;4:248-50.

14. Nanto-Salonen K, Muller HL, Hoffman AR, Vu TH, Rosenfeld RG. Mechanisms of thyroid hormone action on the insulin-like growth factor system: all thyroid hormone effects are not growth hormone mediated. Endocrinology 1993; 132:781-8.

15. Quintos JB, Salas M. Use of growth hormone and gonadotropin releasing hormone agonist in addition to L-thyroxine to attain normal adult height in two patients with severe Hashimoto's thyroiditis. J Pediatr Endocrinol Metab 2005;18:515-21.

16. Nebesio TD, Wise MD, Perkins SM, Eugster EA. Does clinical management impact height potential in children with severe acquired hypothyroidism? J Pediatr Endocrinol Metab 2011;24:893-6. 